\title{
Reasons of not having breast reconstruction: a historical cohort of 1937 breast cancer patients undergoing mastectomy
}

Delphine Héquet ${ }^{1}$, Kevin Zarca², Sylvie Dolbeault ${ }^{3}$, Benoît Couturaud ${ }^{1}$, Charlotte Ngô $^{1}$, Virgine Fourchotte ${ }^{1}$, Anne De La Rochefordière ${ }^{3}$, Jean-Guillaume Féron ${ }^{1}$, Alfred Fitoussi', Catherine Bélichard ${ }^{1}$, Fabien Reyal', Fatima Laki ${ }^{1}$, David Hajage ${ }^{2}$, Brigitte Sigal ${ }^{4}$, Bernard Asselain ${ }^{2}$, and Séverine Alran ${ }^{1,5^{*}}$ Institut Curie Breast Cancer Group, Roman Rouzier

\begin{abstract}
Background: The aims of the study were to investigate the factors associated with not having breast reconstruction following mastectomy and to assess patient satisfaction with information on reconstruction.

Patients and methods: We analysed a historical cohort of 1937 consecutive patients who underwent mastectomy at Institut Curie between January 2004 and February 2007. Their sociodemographic and clinicobiological characteristics were recorded in a prospective database. A questionnaire was sent to $10 \%$ of nonreconstructed patients.

Results: The proportion of patients with invasive cancer was $82.7 \%$. The rate of nonreconstruction in patients with in situ and invasive cancer was $34.6 \%$ and $74.9 \%$, respectively. On multivariate analysis, only employment outside the home was associated with reconstruction in patients with in situ cancer $(p<0.001)$. In patients with invasive cancer, employment status $(p<0.001)$ and smoking $(p=0.045)$ were associated with reconstruction, while age $>50$, ASA score $>1$, radiotherapy $(p<0.0001)$ and metastatic status $(p=0.018)$ were associated with nonreconstruction. For $80 \%$ of questionnaire responders, nonreconstruction was a personal choice, mainly for the following reasons: refusal of further surgery, acceptance of body asymmetry, risk of complications and advanced age. Information on reconstruction was entirely unsatisfactory or inadequate for $62 \%$ of patients.
\end{abstract}

Conclusion: Better understanding the factors that influence decision of nonreconstruction can help us adapt the information to serve the patient's personal needs.

Keywords: Breast cancer; Mastectomy; Breast reconstruction; Personal choice; Medical information

\section{Introduction}

About 52,500 women are diagnosed with breast cancer in France every year (La situation du cancer en France 2010). Breast-conserving therapy is standard procedure for selected patients (Fisher et al. 2002; Veronesi et al. 1995), however, between 2005 and 2009, 26\% of breast cancer patients in France underwent mastectomy (La situation du cancer en France 2010). Only 22.9\% of

\footnotetext{
* Correspondence: severine.alran@curie.net

1 Department of Surgery, Paris, France

${ }^{5}$ Institut Curie, 26 rue d'Ulm, Paris 75005, France

Full list of author information is available at the end of the article
}

patients who undergo mastectomy in France proceed with reconstruction (PMSI national 2011).

Mastectomy and reconstruction rates vary widely from between countries, regionally within countries and over time, making it difficult to produce meaningful comparisons. Nevertheless, what emerges across all studies is that the majority patients do not have reconstruction following mastectomy (Table 1) (Kruper et al. 2011; Jeevan et al. 2010; Hvilsom et al. 2011; Morrow et al. 2001; Reaby 1998; Baxter et al. 2005; Yu et al. 2007; Meyer-Marcotty et al. 2007; Fallbjork et al. 2010; Al-Allak et al. 2010; Al-Ghazal et al. 2000; Harcourt et al. 2003; Christian et al. 2006; Joslyn 2005; Rowland et al. 
Table 1 Reconstruction rates in various countries

\begin{tabular}{|c|c|c|c|c|}
\hline Author & Country & Type of study sample size & Mastectomy rate & Reconstruction rate \\
\hline Reaby et al. (1998) & Australia & Questionnaire $\mathrm{N}=95$ & - & $10 \%$ \\
\hline Baxter et al. (2005) & Canada & Retrospective $N=27718$ & $42.9 \%$ & $7.9 \%$ \\
\hline Yu et al.(2007) & China & Retrospective $N=5887$ & $93.7 \%$ & $5 \%$ \\
\hline Hvilsom et al. (2011) & Denmark & National registry $N=13379$ & $37 \%$ & $25 \%$ \\
\hline Meyer-Marcotty et al. (2007) & Germany & Retrospective $N=4335$ & $34 \%$ & $13 \%$ \\
\hline Fallbjork et al. (2010) & Sweden & Questionnaire $N=149$ & $40 \%$ & $25 \%$ \\
\hline Al-Allak et al.(2010) & United Kingdom & Retrospective $N=272$ & - & $46 \%$ \\
\hline Al-Ghazal et al. (2000) & United Kingdom & Retrospective $\mathrm{N}=577$ & $35 \%$ & $21 \%$ \\
\hline Harcourt et al. (2003) & United Kingdom & Prospective $\mathrm{N}=103$ & - & $46 \%$ \\
\hline Jeevan et al. (2010) & United Kingdom & Registry N = 44837 & $40 \%$ & $16 \%$ \\
\hline Christian et al. (2006) & United States & National registry $N=2174$ & $42 \%$ & $42 \%$ \\
\hline Joslyn (2005) & United States & National registry $N=27703$ & - & $17 \%$ \\
\hline Kruper et al. (2011) & United States & State registry $N=11019$ & $42 \%$ & $25-29 \%$ \\
\hline Morrow et al. (2001) & United States & National registry $N=68348$ & - & $8.3 \%$ \\
\hline Rowland et al. (2000) & United States & Retrospective $N=1957$ & $43 \%$ & $17 \%$ \\
\hline Our study Héquet et al. & France & Retrospective $N=1937$ Questionnaire $N=132$ & $26 \%$ & $32.1 \%$ \\
\hline
\end{tabular}

2000). Numerous studies have looked at the techniques and timing of breast reconstruction, patient satisfaction and quality-of-life after reconstruction, as well as the relative mastectomy/reconstruction rates, and the factors affecting these rates. These studies tend to focus on patients who undergo reconstruction. A few studies have given equal importance to patients who do not have reconstruction (Morrow et al. 2001; Reaby 1998; Fallbjork et al. 2010; Harcourt et al. 2003; Alderman et al. 2003).

To our knowledge, this was the first recent study that proposed to focus specifically on patients who did not have surgical reconstruction. The aim was to gain a better understanding of the factors, both medical and personal, that led to the decision and to consider the implications in terms of patient management and counseling. To that end, we assessed the sociodemographic and clinicobiological factors associated with surgical reconstruction in patients who did not have reconstruction and in patients who did, whether immediate or delayed. In addition, we investigated the reasons why patients did not have surgical reconstruction, and evaluated the information provided to these patients.

\section{Patients and methods}

\section{Study population}

Consecutive patients treated by mastectomy for in situ or invasive breast cancer between January 2004 and December 2007 in Institut Curie (Paris, France), were eligible for inclusion. Exclusion criteria were history of contralateral mastectomy, bilateral mastectomy, mastectomy for benign disease, prophylactic mastectomy, and men. The study was approved by the Breast Cancer
Study Group of Institut Curie, and the questionnaire was approved by the Ethics Committee of Institut Curie.

\section{Data collection}

Data in the medical charts of a historical cohort of 1937 patients were prospectively recorded for analysis. The following factors were studied: age at mastectomy, marital status, professional status, weight (in $\mathrm{kg}$ ), height (in $\mathrm{cm}$ ), breast size, American Society of Anesthesiologists (ASA) score, histological grade of cancer (in situ carcinoma, invasive carcinoma grade I, II, III of the Scarff-Bloom-Richardson classification), tumor size (in $\mathrm{cm}$ ), estrogen-receptor status, progesterone-receptor status, HER2 status, axillary lymph node status, indication of mastectomy (for clinicobiological factors of cancer, after failure of conservative treatment, or for recurrence), and adjuvant therapy (hormone therapy, chemotherapy, radiotherapy).

\section{Questionnaire}

A questionnaire was sent to a $10 \%$ sample of patients who did not have reconstruction $(n=132)$, including every tenth patient in the retrospective database. The questionnaire was prepared in collaboration with a panel of 8 patients who had undergone mastectomy only and a panel of medical and paramedical professionals working in the field of breast cancer. The questionnaire was sent out in June 2011. Responders remained anonymous. All questions were multiple choice, and patients could provide more than one response. At the end of the questionnaire, free-text comments could be added. The 
Table 2 Characteristics of the population

\begin{tabular}{|c|c|}
\hline & All patients $(\mathrm{N}=19$ \\
\hline Age (years) - median (range) & $56(23-97)$ \\
\hline \multicolumn{2}{|l|}{ Marital status - N (\%) } \\
\hline Not partnered & $411(21.3)$ \\
\hline Partnered & $651(33.6)$ \\
\hline Unknown & $875(45.1)$ \\
\hline \multicolumn{2}{|l|}{ Employment status - N (\%) } \\
\hline Not working outside home & $609(31.4)$ \\
\hline Working outside home & $900(46.5)$ \\
\hline Unknown & $428(22.1)$ \\
\hline \multicolumn{2}{|l|}{$\mathrm{BMI}^{\mathrm{a}}\left(\mathrm{kg} / \mathrm{m}^{2}\right)-\mathrm{N}(\%)$} \\
\hline$<20$ & $292(15.1)$ \\
\hline $20-25$ & $925(47.8)$ \\
\hline $26-30$ & $450(23.2)$ \\
\hline$>30$ Unknown & $221(11.4) 49$ (2.5) \\
\hline Breast size $(\mathrm{cm})$ - median (range) & $90(65-130)$ \\
\hline \multicolumn{2}{|l|}{ Cup size - N (\%) } \\
\hline A & $108(5.6)$ \\
\hline B & $521(26.9)$ \\
\hline C & $299(15.4)$ \\
\hline$\geq D$ & $183(9.5)$ \\
\hline Unknown & $826(42.6)$ \\
\hline Tobacco users - N (\%) & $296(15.3)$ \\
\hline \multicolumn{2}{|l|}{ ASA $^{\mathrm{b}}$ score - N (\%) } \\
\hline ASA 1 & $1051(54.2)$ \\
\hline ASA 2 & $824(42.6)$ \\
\hline$A S A>2$ & $62(3.2)$ \\
\hline \multicolumn{2}{|l|}{ Histologic stage - N (\%) } \\
\hline In situ & $335(17.3)$ \\
\hline$S B R^{C} /$ & $217(11.2)$ \\
\hline$S B R \|$ & $716(37)$ \\
\hline SBR III & $614(31.7)$ \\
\hline Invasive SBR unknown & $54(2.8)$ \\
\hline \multicolumn{2}{|l|}{ Tumor size (cm) - N (\%) } \\
\hline$<2$ & $603(31.2)$ \\
\hline $2-5$ & $919(47.5)$ \\
\hline$>5$ & $316(16.3)$ \\
\hline Unknown & $98(5)$ \\
\hline Estrogen receptors positive - N (\%) & $1251(64.6)$ \\
\hline Progesterone receptors positive - N (\%) & $444(22.9)$ \\
\hline Overexpression HER2 - N (\%) & $228(11.8)$ \\
\hline Axillary lymph nodes positive - N (\%) & $726(37.5)$ \\
\hline Inflammatory cancer - N (\%) & $92(4.8)$ \\
\hline Metastatic cancer - N (\%) & $83(4.3)$ \\
\hline
\end{tabular}

Table 2 Characteristics of the population (Continued)

\begin{tabular}{|c|c|}
\hline Clinicobiological characteristics of cancer & $1061(54.8)$ \\
\hline Failure conservative surgery & $357(18.4)$ \\
\hline Local recurrence & $519(26.8)$ \\
\hline \multicolumn{2}{|l|}{ Chemotherapy - N (\%) } \\
\hline Adjuvant & $715(36.9)$ \\
\hline Neoadjuvant & $284(14.7)$ \\
\hline Radiotherapy - N (\%) & $971(50.2)$ \\
\hline Hormone therapy - N (\%) & $1175(60.7)$ \\
\hline
\end{tabular}

responses were analyzed descriptively, and free-text comments were collected.

\section{Analysis}

The sociodemographic and clinicobiological factors associated with reconstruction were assessed in two groups: patients who did not have reconstruction and patients who had immediate or delayed reconstruction. Univariate analysis was performed using Chi-square test for categorical variables and Student's $t$-test for continuous variables. Multivariate analysis was performed using logistic regression models on two groups: patients with in situ cancer and patients with invasive cancer. Variables associated with reconstruction $(P<0.10)$ in the univariate analysis were introduced into the multivariate model, as more traditional approaches, such as considering all variables with $P<0.05$ in the univariate analysis, can fail to identify variables known to be important. A $P$-value $<0.05$ was considered statistically significant.

\section{Results}

Description of the cohort

Among the 1937 patients included, 1315 (67.9\%) had no surgical reconstruction and $622(32.1 \%)$ patients had surgical reconstruction, which was immediate in 363 patients (58.5\%) and delayed in 259 patients (41.5\%). Among patients who ultimately had delayed reconstruction, the median time to reconstruction was 19 months (range: 3-77 months).

Patient characteristics are summarized in Table 2.

\section{Factors associated with not having surgical breast reconstruction \\ In situ cancer}

Mastectomy was indicated for in situ cancer in 335 patients (17.3\%). The nonreconstruction rate was $34.6 \%$. The reconstruction rate was $65.4 \%$ immediate in $82.6 \%$ of cases and delayed in only $17.4 \%$ of cases. Univariate analysis showed a statistical difference between 
Table 3 Univariate analysis in $\mathbf{3 3 5}$ patients with in situ cancer

\begin{tabular}{|c|c|c|c|}
\hline & Nonreconstructed $\mathrm{N}=116$ & Reconstructed N = 219 & P-value \\
\hline Age (years) - median (range) & $57(23-86)$ & $50(26-75)$ & $<0.001$ \\
\hline Marital status - N (\%) & & & 0.134 \\
\hline Not partnered & $28(42.4)$ & $40(30.5)$ & \\
\hline Partnered & $38(57.6)$ & $91(69.5)$ & \\
\hline Employment status - N (\%) & & & $<0.001$ \\
\hline Not working outside home & $46(48.9)$ & $39(21.3)$ & \\
\hline Working outside home & $48(51.1)$ & $144(78.7)$ & \\
\hline$B M l^{a}\left(k g / m^{2}\right)-N(\%)$ & & & 0.391 \\
\hline$<20$ & $23(20.2)$ & $42(19.3)$ & \\
\hline $20-25$ & $59(51.8)$ & $123(56.4)$ & \\
\hline $26-30$ & $20(17.5)$ & $41(18.8)$ & \\
\hline$>30$ & $12(10.5)$ & $12(5.5)$ & \\
\hline Tobacco users - N (\%) & $15(12.9)$ & $38(17.4)$ & 0.369 \\
\hline ASA $A^{b}$ score - N (\%) & & & 0.004 \\
\hline ASA 1 & $64(55.2)$ & $157(71.7)$ & \\
\hline ASA 2 & $48(41.4)$ & $60(27.4)$ & \\
\hline$A S A>2$ & $4(3.4)$ & $2(0.9)$ & \\
\hline Tumor size $(\mathrm{cm})$ - N (\%) & & & 0.123 \\
\hline$<2$ & $29(27.1)$ & $41(23.7)$ & \\
\hline $2-5$ & $56(52.3)$ & $77(44.5)$ & \\
\hline$>5$ & $22(20.6)$ & $55(31.8)$ & \\
\hline Indication of mastectomy - N (\%) & & & 0.612 \\
\hline Clinicobiological characteristics of cancer & $57(49.1)$ & $96(43.8)$ & \\
\hline Failure conservative surgery & 39 (33.6) & 78 (35.6) & \\
\hline Local recurrence & $20(17.2)$ & $45(20.5)$ & \\
\hline
\end{tabular}

${ }^{a} B M I$ body mass index.

${ }^{b}$ ASA American Society of Anesthesiologists.

reconstructed and nonreconstructed patients for several factors (Table 3). Reconstructed patients were 7 years younger than nonreconstructed patients $(P<0.001)$. Not working outside the home was more frequent in nonreconstructed patients $(48.9 \%$ versus $21.3 \%, P<0.001)$. Twenty-eight percent of reconstructed patients had an ASA score above 1 , while $44.8 \%$ of nonreconstructed patients had a score above $1(P=0.004)$.

In the multivariate analysis, only employment status was statistically different between the 2 groups, with 4 times more patients in the reconstructed group working outside the home (OR: 4.05; CI: 2.05-8.00; $P<0.001)$. No statistically significant difference was found for the other criteria (Table 4).

\section{Invasive cancer}

Mastectomy was indicated for invasive cancer in 1602 patients $(82.7 \%)$. The nonreconstruction rate was $74.9 \%$.
The reconstruction rate was $25.1 \%$ immediate in $45 \%$ of cases and delayed in $55 \%$ of cases.

Univariate analysis showed that reconstructed patients were 9 years younger than nonreconstructed patients (Table 5). Forty-nine percent of nonreconstructed patients were not working outside the home, compared to only $22 \%$ of reconstructed patients $(P<0.001)$. High Body Mass Index $\left(>25 \mathrm{~kg} / \mathrm{m}^{2}\right)$ was more frequent in nonreconstructed patients $(41.1 \%$ versus $27.7 \%, P<0.001)$. Smoking was more frequent in reconstructed patients (20.9\% versus $13.3 \%, P<0.001$ ). Positive axillary lymphnode or metastatic status was more frequent in nonreconstructed patients $(48.3 \%$ versus $36.5 \%, P<0.001$ and $6.4 \%$ versus $2.2 \%, P=0.002$ respectively). Radiotherapy was more frequent in nonreconstructed patients $(60 \%$ versus $52.7 \%, P=0.012$ ).

In the multivariate analysis, reconstruction was less frequent when the following factors were present: age over 50 (OR: 0.22; CI: 0.11-0.44; $P<0.001$ ), ASA score 
Table 4 Multivariate analysis for breast reconstruction

\begin{tabular}{|c|c|c|c|c|c|c|}
\hline & \multicolumn{3}{|c|}{ Patients with in situ cancer $\mathrm{N}=335$} & \multicolumn{3}{|c|}{ Patients with invasive cancer $\mathrm{N}=1602$} \\
\hline & $\mathrm{OR}^{\mathrm{a}}$ & $\mathrm{Cl}^{\mathrm{b}}$ & P-value & OR & $\mathrm{Cl}$ & P-value \\
\hline Age (years) & & & 0.091 & & & $<0.001$ \\
\hline$<35$ & 1.00 & & & 1.00 & & \\
\hline $35-50$ & 0.92 & $0.23-3.72$ & & 0.45 & $0.24-0.86$ & \\
\hline$>50$ & 0.45 & $0.11-1.84$ & & 0.22 & $0.11-0.44$ & \\
\hline Employment status & & & $<0.001$ & & & $<0.001$ \\
\hline Not working outside home & 1.00 & & & 1.00 & & \\
\hline Working outside home & 4.05 & $2.05-8.00$ & & 2.07 & $1.37-3.13$ & \\
\hline $\mathrm{BMl}^{\mathrm{C}}\left(\mathrm{kg} / \mathrm{m}^{2}\right)$ & & & 0.420 & & & 0.078 \\
\hline$<20$ & 1.00 & & & 1.00 & & \\
\hline $20-25$ & 1.79 & $0.80-4.00$ & & 1.30 & $0.83-2.02$ & \\
\hline $26-30$ & 2.21 & $0.81-6.03$ & & 0.80 & $0.46-1.38$ & \\
\hline$>30$ & 1.91 & $0.53-6.84$ & & 1.50 & $0.80-2.82$ & \\
\hline Tobacco users & & & & & & 0.045 \\
\hline No & & & & 1.00 & & \\
\hline Yes & & & & 1.52 & $1.01-2.28$ & \\
\hline ASA $^{\text {d }}$ score & & & 0.155 & & & $<0.001$ \\
\hline ASA 1 & 1.00 & & & 1.00 & & \\
\hline ASA 2 & 0.63 & 0.33-1.19 & & 0.51 & $0.36-0.73$ & \\
\hline$A S A>2$ & & & & 0.00 & & \\
\hline Tumor size $(\mathrm{cm})$ & & & 0.232 & & & 0.655 \\
\hline$<2$ & 1.00 & & & 1.00 & & \\
\hline $2-5$ & 0.58 & $0.27-1.24$ & & 1.09 & $0.75-1.58$ & \\
\hline$>5$ & 0.94 & $0.39-2.25$ & & 1.28 & $0.76-2.14$ & \\
\hline Metastatic cancer & & & & & & 0.018 \\
\hline No & & & & 1.00 & & \\
\hline Yes & & & & 0.34 & $0.13-0.91$ & \\
\hline Indication of mastectomy & & & & & & 0.024 \\
\hline Clinicobiological characteristics of cancer & & & & 1.00 & & \\
\hline Failure conservative surgery & & & & 1.27 & $0.84-1.91$ & \\
\hline Local recurrence & & & & 2.09 & $1.23-3.55$ & \\
\hline Chemotherapy & & & & & & 0.748 \\
\hline No & & & & 1.00 & & \\
\hline Adjuvant & & & & 0.94 & $0.60-1.47$ & \\
\hline Neoadjuvant & & & & 0.81 & $0.46-1.43$ & \\
\hline Radiotherapy & & & & & & $<0.001$ \\
\hline No & & & & 1.00 & & \\
\hline Yes & & & & 0.57 & $0.38-0.86$ & \\
\hline
\end{tabular}

\footnotetext{
${ }^{a}$ OR odds ratio.

${ }^{b} \mathrm{Cl}$ confidence interval.

${ }^{c} B M I$ body mass index.

${ }^{d}$ ASA American Society of Anesthesiologists.
}

above 1 (OR: 0.51; CI: 0.36-0.73; $P<0.001$ ), metastatic status (OR: 0.34 ; CI: $0.13-0.91 ; P=0.018$ ), and radiotherapy (OR: 0.57 ; CI: $0.38-0.86 ; P<0.001$ ). The following factors were associated with reconstruction: working outside the home (OR: 2.07; CI: 1.37-3.13; $P<0.001$ ), smoking (OR: 1.52; CI: 1.01-2.28; $P=0.045$ ), HER2 
Table 5 Univariate analysis in 1602 patients with invasive cancer

\begin{tabular}{|c|c|c|c|}
\hline & Nonreconstructed $\mathrm{N}=1200$ & Reconstructed $\mathrm{N}=402$ & P-value \\
\hline Age (years) - median (range) & $59.6(28-97)$ & $50.5(25-76)$ & $<0.001$ \\
\hline Marital status - N (\%) & & & 0.171 \\
\hline Not partnered & $266(41.1)$ & $77(35.5)$ & \\
\hline Partnered & $382(59)$ & $140(64.5)$ & \\
\hline Employment status - N (\%) & & & $<0.001$ \\
\hline Not working outside home & $457(49.4)$ & $67(21.9)$ & \\
\hline Working outside home & $469(50.6)$ & $239(78.1)$ & \\
\hline$B M l^{a}\left(k g / m^{2}\right)-N(\%)$ & & & $<0.001$ \\
\hline$<20$ & $158(13.6)$ & $69(17.5)$ & \\
\hline $20-25$ & $527(45.3)$ & $216(54.8)$ & \\
\hline $26-30$ & $317(27.3)$ & $72(18.3)$ & \\
\hline$>30$ & $160(13.8)$ & $37(9.4)$ & \\
\hline Tobacco users - N (\%) & $159(13.3)$ & $84(20.9)$ & $<0.001$ \\
\hline ASA ${ }^{b}$ score - N (\%) & & & $<0.001$ \\
\hline ASA 1 & $557(46.5)$ & $272(67.7)$ & \\
\hline ASA 2 & $588(49)$ & $128(31.8)$ & \\
\hline$A S A>2$ & $54(4.5)$ & $2(0.05)$ & \\
\hline Tumor size $(\mathrm{cm})$ - N (\%) & & & 0.004 \\
\hline$<2$ & $377(32)$ & $156(40.9)$ & \\
\hline $2-5$ & $619(52.6)$ & $167(43.8)$ & \\
\hline$>5$ & $181(15.4)$ & $58(15.2)$ & \\
\hline Axillary lymph nodes positive N (\%) Median (range) & $579(48.3 \%) 1(0-28)$ & $147(36.5) 0(0-19)$ & $<0.001$ \\
\hline Metastatic cancer - N (\%) & $76(6.4)$ & $9(2.2)$ & 0.002 \\
\hline Indication of mastectomy - N (\%) & & & $<0.001$ \\
\hline Clinicobiological characteristics of cancer & $720(60.1)$ & $187(46.5)$ & \\
\hline Failure conservative surgery & $162(13.5)$ & $78(19.4)$ & \\
\hline Local recurrence & $317(26.4)$ & $137(34.1)$ & \\
\hline Chemotherapy - N (\%) & & & 0.253 \\
\hline Adjuvant & $501(41.8)$ & $187(46.5)$ & \\
\hline Neoadjuvant & $208(17.3)$ & $64(15.9)$ & \\
\hline Radiotherapy - N (\%) & $720(60)$ & $212(52.7)$ & 0.012 \\
\hline Hormone therapy - N (\%) & $853(71.1)$ & $283(70.4)$ & 0.825 \\
\hline
\end{tabular}

${ }^{a} B M I$ body mass index.

${ }^{\mathrm{b}}$ ASA American Society of Anesthesiologists.

overexpression (OR: 1.75 , CI: $1.13-2.70, P=0.029$ ), and mastectomy indicated for local recurrence (OR: 2.09; CI: $1.23-3.55 ; P=0.024)$. The results are presented in Table 4 .

\section{Reasons for not having surgical reconstruction}

The response rate to the questionnaire was $61.4 \%$ (81 patients).

Forty-nine patients $(80 \%)$ declared that the decision not to have reconstruction was a personal choice. Eleven patients $(18 \%)$ declared that reconstruction was not offered by the surgeon. Twelve patients (19.7\%) declared that the decision was a personal choice and that reconstruction was not offered by the surgeon. Five patients $(8.2 \%)$ declared that reconstruction was not undertaken for medical reasons.

The reasons for deciding not to have reconstruction, among patients who declared that the decision was a personal choice, are shown in Table 6.

Evaluation of information on surgical breast reconstruction Analysis of the responses to questions concerning the source of information on reconstruction and patient satisfaction is shown in Table 6. 
Table 6 Analysis of questionnaire data

\begin{tabular}{|c|c|c|}
\hline & $\mathbf{N}$ & $\%$ \\
\hline Questionnaires sent out & 132 & 100 \\
\hline Questionnaires returned & 81 & 61.4 \\
\hline Non-respondents (i.e. refused to participate, deceased or subsequently reconstructed) & 20 & 24.7 \\
\hline Respondents & 61 & 75.3 \\
\hline \multicolumn{3}{|l|}{ Reason for nonreconstruction } \\
\hline Personal choice & 33 & 54.1 \\
\hline Not offered by surgeons and personal choice & 12 & 19.7 \\
\hline Not offered by surgeons & 11 & 18 \\
\hline Medical reasons and personal choice & 4 & 6.6 \\
\hline Medical reasons & 1 & 1.6 \\
\hline \multicolumn{3}{|l|}{ Personal choice } \\
\hline Refusal of further surgery & 36 & 59 \\
\hline Acceptance of body asymmetry & 23 & 37.7 \\
\hline Risk of complications & 18 & 29.5 \\
\hline Advanced age & 14 & 23 \\
\hline Fear of masking recurrence & 11 & 18 \\
\hline Acceptance of body asymmetry by partner & 11 & 18 \\
\hline Financial cost & 9 & 14.8 \\
\hline Post-mastectomy pain & 4 & 6.6 \\
\hline \multicolumn{3}{|l|}{ Source of information on reconstruction } \\
\hline Surgeon at $1 C^{a}$ & 21 & 34.4 \\
\hline Plastic surgeon at $\mathrm{IC}$ & 8 & 13.1 \\
\hline Physician outside IC & 7 & 11.5 \\
\hline Physician or nurse at IC & 7 & 11.5 \\
\hline Relative with history of reconstruction & 6 & 8.8 \\
\hline Internet, review, magazine & 5 & 8.2 \\
\hline Patients association & 3 & 4.9 \\
\hline IC website or review & 3 & 4.9 \\
\hline Plastic surgeon outside IC & 2 & 3.3 \\
\hline \multicolumn{3}{|l|}{ Satisfaction with information on reconstruction } \\
\hline Entirely unsatisfactory & 25 & 41 \\
\hline Inadequate & 13 & 21.3 \\
\hline Adequate & 17 & 27.9 \\
\hline Entirely satisfactory & 6 & 9.8 \\
\hline
\end{tabular}

a IC Institut Curie.

\section{Discussion}

In France, the reconstruction rate is around 23\% (PMSI national 2011). The rate is $32.1 \%$ at Institut Curie, a national cancer institute in Paris. Other studies have shown that reconstruction rates tend to be higher in specialized cancer-treatment centers (Kruper et al. 2011; Jeevan et al. 2010; Hvilsom et al. 2011; Morrow et al. 2001), and our study supports this finding, with a reconstruction rate well above the national average.
Previous studies have shown that younger patients are more likely to have reconstruction compared to older patients (Kruper et al. 2011; Jeevan et al. 2010; Morrow et al. 2001; Reaby 1998; Fallbjork et al. 2010; Al-Allak et al. 2010; Christian et al. 2006; Joslyn 2005; Rowland et al. 2000). In our study, age over 50 was significantly associated with nonreconstruction in patients with invasive cancer, but only approached significance in patients with in situ cancer. It has been theorized that this 
difference may reflect physicians' attitudes, the fact that older women attach less importance to body image, or that they have more comorbidities. A recent review on reconstruction in older patients cites the fear of complications as a major dissuasive factor, even though studies have shown that age in itself is not a risk factor for poor surgical outcomes (Walton et al. 2011).

Pathology tumor stage has also been shown to be an important predictor of nonreconstruction (Morrow et al. 2001; Christian et al. 2006; Joslyn 2005). In our study, patients with primary invasive cancer were much less likely to undergo reconstruction than those with in situ cancer or local recurrence. The probable explanation is that, in the latter two cases, reconstruction can be performed at the same time as mastectomy, thereby limiting the number of additional surgical interventions, as illustrated by the fact that, in almost $83 \%$ of patients with in situ cancer who had reconstruction, the procedure was immediate. In addition, these patients did not receive post-operative radiotherapy. In our study, in patients with invasive cancer, radiotherapy significantly reduced the odds of having reconstruction, however confounding factors may be present, including cancer stage and type of reconstruction. In most patients with a history of radiotherapy, autologous reconstruction is required because the complication rate with implant-based reconstruction is greater than 40\% (Barry \& Kell 2011; Kronowitz \& Robb 2009). The advantages and disadvantages of the different techniques enter into the patient's final decision as concerns delayed reconstruction (Alderman et al. 2002; Cordeiro \& McCarty 2006; Rouzier et al. 2000).

For the majority of patients, the decision not to have nonreconstruction was reportedly a personal choice. The major reason was refusal of further surgery. Clearly it is legitimate for patients to be reluctant to have surgery that is not necessarily perceived to be an integral part of treatment of the disease as such. Patients' concerns about the number of surgeries and the duration of recovery may outweigh the potential benefits in terms of cosmesis and quality of life.

Acceptance of body asymmetry by the patient herself and/or by her partner was frequently reported as the reason for not having reconstruction. This finding points to a potential weakness in the study, i.e. the fact that the questionnaire was sent out several years after the initial decision concerning reconstruction was taken. As a result, the responses probably reflect to some extent what patients considered to be the reason(s) for not having reconstruction at the time of filling out the questionnaire. Nevertheless, the decision is not necessarily taken 'once and for all'. The availability of delayed reconstruction means that the option may remain open for several years after mastectomy, as illustrated by the fact that, at the time of analysis in our study, the median time to delayed reconstruction was about $1 \frac{1}{2}$ years, with a maximum of almost $6 \frac{1}{2}$ years. For this reason, while we recognize it as a potential weakness, we do not believe that it undermines the validity of the finding.

The risk of complications was reported as the reason for not having reconstruction by almost 30\% of patients, which is lower than the percentages seen in other studies (Shameem et al. 2008; Alderman \& Jagsi 2010). Endorsement of this reason indicates that the patients were aware of the potential complications. Although the source of the information could not be ascertained, a recent review by Potter et al. highlights problems in reporting outcomes in reconstruction, particularly as concerns the assessment of surgical complications (Potter et al. 2010).

Fear of masking recurrence of the disease was reported by $18 \%$ of patients. Considerably higher percentages have been reported elsewhere (Shameem et al. 2008; Alderman \& Jagsi 2010), even though studies going back as far as the mid-1990s do not support the fear that reconstruction might interfere with postoperative cancer surveillance. This finding has obvious implications in terms of patient counseling, suggesting that, with better information, patients might overcome their fear.

Age was not listed among the multiple-choice responses on the questionnaire, but was added in the free-text section 'Other reason(s)' by almost a quarter of patients, making this an important finding. The reasons why age in itself should be a major factor have not been fully elucidated, but certainly merit further investigation.

As expected, financial considerations were not a major factor since, under the publicly funded healthcare system in France, patients do not have to pay for the procedure, theoretically at least. In practice, however, access to reconstruction in public institutions is restricted by the limited number of surgeons and availability of operating theaters. As a result, a number of patients in France are led to consult in private hospitals, which entails additional costs, borne by the patient herself or by patientfunded complementary health insurance. Financial cost as a reason for not having reconstruction, as reported by $14 \%$ of patients, reflects a problem of access to the procedure within our institution.

Finally, post-mastectomy pain was reported by $6.5 \%$ of patients. Similar to acceptance of body asymmetry, this reason for not having reconstruction reflects the ongoing nature of the decision and is relevant only to patients who were offered or were considering delayed reconstruction. It suggests the need for better control of complications following mastectomy.

Sixty-one patients completed the questions related to the source of and satisfaction with information on reconstruction. While the questionnaire did not preclude 
patients from citing more than one response, only one respondent cited two sources of information, pointing to another potential weakness in our findings. More than three-quarters of patients reported that the information had been received from a medical source, most often (63\%) a source within Institut Curie: a surgeon, a plastic surgeon, a doctor or nurse, or from the Institut website or review (Table 6), however the actual proportion is almost certainly even higher. Although provision of information is not recorded in patients' files, standard procedures at Institut Curie make it nearly impossible for a patient who is eligible for reconstruction not to be informed of this option.

It is therefore noteworthy that, in $40 \%$ of patients overall, the decision was taken after receiving information they considered to be 'entirely unsatisfactory'. A similar figure was found in the National Mastectomy and Breast Reconstruction Audit in 2010, in which $41.6 \%$ of mastectomy-only patients reported they had been "given no information" (Mayor 2010). As concerns our finding, it is probably not only a question of quantity or even of quality, but also of timing and the method of delivering information prior to mastectomy, i.e. at a time when many patients may not be highly receptive.

Another study has been set up to investigate the provision of information in our institution, involving patients and care-givers on an equal footing.

\section{Conclusions}

The majority of patients with breast cancer who undergo mastectomy do not proceed with breast reconstruction. The decision involves multiple factors, some biological and socio-demographic, as well as personal choice. Almost two-thirds of patients were unsatisfied with the information they received. We believe efforts must be made to improve the type and timing of delivering information in order to ensure that patients receive the information they require. By better understanding the factors that the patient takes into consideration in making her decision, we can adapt the information to serve the patient's personal needs and to support the patient in making an informed personal choice on approaches to reconstruction following mastectomy. Future studies must be directed with patients themselves to improve the type and timing of delivering information on different ways of reconstruction.

\section{Previous presentations of this manuscript}

Presented in part at the 33ème Journées de la Société Française de Sénologie et Pathologie Mammaire, November 8-13, 2011, Marseille, France.

Presented in part at the 8th European Breast Cancer Conference, March 21-24, 2012, Vienna, Austria.

\section{Ethical approval}

This study was conducted according to the institutional and ethical rules concerning research on tissue specimens and patients and exempted from requiring informed consent from the patients.

\section{Competing interests}

The authors declare that they have no competing interest.

\section{Authors' contributions}

DeH carried out data collection and drafted the manuscript. KZ performed the statistical analyses. SD drafted the manuscript. BC carried out data collection. CN drafted the manuscript. VF carried out data collection. ADLR drafted the manuscript. JGF, AF, CB, FR and FL carried out data collection. $\mathrm{DaH}$ performed the statistical analyses. BS carried out data collection. BA performed the statistical analyses. SA was the principal investigator and drafted the manuscript. All authors read and approved the final manuscript.

\section{Acknowledgements}

Bernard Baranger (Head of Oncology Surgery Department) and François Doz (Head of Clinical Research) for their support in this project.

Graham Smith, for editorial assistance.

Béatrice Le Vu (Medical Information Department) for data collection.

Stéphane Radoykov, medical student for assistance with data collection. Catherine Malhouitre, breast cancer patient (President of the Association

"Au sein de sa difference") for her personal approach to "overall reconstruction".

Virginie Morin and Nadia Atmani for help with logistics (panel meeting, questionnaire)

The staff nurses who take care of our patients.

Lydie Wintz, principal nurse of the surgery department.

The patients, who actively participated in the panel discussion and patients who answered the questionnaire.

\section{Author details}

'Department of Surgery, Paris, France. ${ }^{2}$ Department of Biostatistics, Paris, France. ${ }^{3}$ Department of Psycho-oncology, Paris, France. ${ }^{4}$ Department of Radiotherapy and Pathology, Paris, France. ${ }^{5}$ Institut Curie, 26 rue d'Ulm, Paris 75005, France.

Received: 20 June 2013 Accepted: 26 June 2013

Published: 18 July 2013

\section{References}

Al-Allak A, Knight H, Walter C et al (2010) Breast reconstruction surgery following mastectomy: love or money? Cancer Res 70(24), Abstract P1-10-08

Alderman AK, Jagsi R (2010) Discussion: immediate post-mastectomy breast reconstruction followed by radiotherapy: risk factors for complications. Breast Cancer Res Treat 121:635-637

Alderman AK, Wilkins EG, Kim HM et al (2002) Complications in postmastectomy breast reconstruction: two-year results of the Michigan breast reconstruction outcome study. Plast Reconstr Surg 109:2265-74

Alderman AK, McMahon L Jr, Wilkins EG (2003) The national utilization of immediate and early delayed breast reconstruction and the impact of sociodemographic factors. Plast Reconstr Surg 111:695-703

Al-Ghazal SK, Fallowfield L, Blamey RW (2000) Comparison of psychological aspects and patient satisfaction following breast conserving surgery, simple mastectomy and breast reconstruction. Eur J Cancer 36:1938-1943

Barry M, Kell R (2011) Radiotherapy and breast reconstruction: a meta-analysis. Breast Cancer Res Treat 127(1):15-22

Baxter N, Goel V, Semple JL (2005) Utilization and regional variation of breast reconstruction in Canada. Plast Reconst Surg 115(1):338-339

Christian CK, Niland J, Edge SB et al (2006) A multi-institutional analysis of the socioeconomic determinants of breast reconstruction. Ann Surg 243(2):241-249

Cordeiro PG, McCarty CM (2006) A single surgeon's 12-year experience with tissue expander/implant breast reconstruction: part I. A prospective analysis of early complications. Plast Reconst Surg 118:825-31 
Fallbjork U, Karlsson S, Salender P et al (2010) Differences between women who have and have not undergone breast reconstruction after mastectomy due to breast cancer. Acta Oncol 49:174-179

Fisher B, Anderson S, Bryant J et al (2002) Twenty-year follow-up of a randomized trial comparing total mastectomy, wide local excision, and wide local excision plus irradiation for the treatment of invasive breast cancer. N Engl J Med 347:1233-1241

Harcourt DM, Rumsey NJ, Ambler NR et al (2003) The psychological effect of mastectomy with or without breast reconstruction: a prospective, multicenter study. Plast Reconstr Surg 111:1060-1068

Hvilsom GB, Holmich LR, Frederiksen K et al (2011) Socioeconomic position and breast reconstruction in Danish women. Acta Oncol 50:265-273

Jeevan R, Cromwell DA, Browne JP et al (2010) Regional variation in use of immediate breast reconstruction for breast cancer in England. Eur J Surg Oncol 36:750-755

Joslyn SA (2005) Patterns of care for immediate and early delayed breast reconstruction following mastectomy. Plast Reconstr Surg 115(5):1289-1296

Kronowitz SJ, Robb GL (2009) Radiation therapy and breast reconstruction: a critical review of the literature. Plast Reconstr Surg 124:395-408

Kruper L, Holt A, Xu XX et al (2011) Disparities in reconstruction rates after mastectomy: patterns of care and factors associated with the use of breast reconstruction in Southern California. Ann Surg Oncol 18:2158-2165

La situation du cancer en France (2010) Institut National du Cancer, http://www.e-cancer.fr/

Mayor S (2010) National audit of care after mastectomy points to need for better information on reconstruction. BMJ 340:c3506

Meyer-Marcotty MV, Hankiss J, Flügel M, Redeker J (2007) Breast reconstruction for patients with breast carcinoma: an analysis based on the data of 4335 patients from 16 hospitals. Chirurg 78(7):637-642

Morrow M, Scott SK, Menck HR et al (2001) Factors influencing the use of breast reconstruction post mastectomy: a national cancer database study. J Am Coll Surg 192:1-8

PMSI national (2011) Institut National du Cancer, http://lesdonnees.e-cancer.fr/

Potter S, Brigic A, Whiting PF, Cawthorn SJ, Avery KNL, Donovan JL, Blazeby JM (2010) Reporting clinical outcomes of breast reconstruction: a systematic review. J Natl Cancer Inst 103(1):31-46

Reaby $L$ (1998) Reasons why women who have mastectomy decide to have or not to have breast reconstruction. Plast Reconst Surg 101(7):1810-1818

Rouzier R, Louis-Sylvestre C, Nos C, Fitoussi A, Clough KB (2000) Autologous breast reconstruction with latissimus dorsi flap. Ann Chir Plast Esthet 45:583-8

Rowland JH, Desmond KA, Meyerowitz BE et al (2000) Role of breast reconstructive surgery in physical and emotional outcomes among breast cancer survivors. J Natl Cancer Inst 92:1422-1429

Shameem H, Yip CH, Fong E (2008) Immediate breast reconstruction after mastectomy - Why do women choose this option? Asian Pac J Cancer Prev 9:409-12

Veronesi U, Salvadori B, Luini A et al (1995) Breast conservation is a safe method in patients with small cancer of the breast. Long-term results of three randomised trials on 1973 patients. Eur J Cancer 31A:1574-1579

Walton L, Ommen K, Audiscio RA (2011) Breast reconstruction in elderly women breast cancer: a review. Cancer Treat Rev 37:353-357

Yu KD, Di GH, Wu J, Lu JS et al (2007) Development and trends of surgical modalities for breast cancer in China: a review of 16-year data. Ann Surg Oncol 14(9):2502-2509

\section{doi:10.1186/2193-1801-2-325}

Cite this article as: Héquet et al:: Reasons of not having breast reconstruction: a historical cohort of 1937 breast cancer patients undergoing mastectomy. SpringerPlus 2013 2:325.

\section{Submit your manuscript to a SpringerOpen ${ }^{\odot}$ journal and benefit from:}

- Convenient online submission

- Rigorous peer review

- Immediate publication on acceptance

- Open access: articles freely available online

- High visibility within the field

- Retaining the copyright to your article

Submit your next manuscript at $\gg$ springeropen.com 